\title{
QUALIDADE DE VIDA DOS PROFESSORES DA ÁREA DE CIÊNCIAS EM ESCOLA PÚBLICA NO RIO GRANDE DO SUL
}

QUALITY OF LIFE OF PUBLIC SCHOOL SCIENCE TEACHERS IN RIO GRANDE DO SUL, BRAZIL

\author{
Liliani Mathias Brum ${ }^{1}$ \\ Cati Reckelberg Azambuja ${ }^{2}$ \\ João Felipe Peres Rezer ${ }^{3}$ \\ Daiana Sonego Temp ${ }^{4}$ \\ Cristiane Köhler Carpilovsky ${ }^{5}$ \\ Luis Felipe Lopes ${ }^{6}$ \\ Maria Rosa Chitolina Schetinger ${ }^{7}$
}

Resumo A investigação da qualidade de vida dos professores de ciências e a busca por melhorias que promovam um melhor desempenho desses profissionais no cotidiano das escolas podem ser uma forma de reduzir as desigualdades na educação no Brasil e favorecer o crescimento dos professores em nível educacional e social. Este estudo teve o objetivo de analisar indicadores físicos e mentais de qualidade de vida dos professores de ciências de uma escola pública localizada no interior do Rio Grande do Sul. Foram avaliadas informações acerca das características demográficas, econômicas, ocupacionais, atividades domésticas, esforços físicos, saúde física, saúde mental e os diagnósticos médicos mais referidos pelos professores desde o início do trabalho como docente. Como resultados, encontraram-se diversas queixas em relação à saúde e à qualidade de vida dos professores estudados, como nervosismo, rouquidão, dor nas costas, braços e pernas, além de formigamento e inchaço nas pernas. Conclui-se que o conhecimento dessas evidências pode contribuir para a construção de medidas para a reorganização da sistemática de trabalho e influenciar diretamente na qualidade de vida dos professores, gerando melhor desempenho na atividade de educar.

Palavras-chave qualidade de vida; professores; ciência/educação; escolas.
Abstract The investigation regarding the quality of life of science teachers and the search for improvements that ameliorate these professionals' performance in primary education schools can be a way to reduce inequalities in education in Brazil and help teachers progress, not only from the educational but also from the social viewpoint. This study aimed to analyze indicators of physical and mental quality of life among science teachers in a public school located in the interior of Rio Grande do Sul, Brazil. The information that was assessed included the demographic, economic, occupational and domestic characteristics, data on physical exertion and health, on mental health conditions, as well as the medical diagnoses most frequently mentioned by the teachers ever since they started working in the profession. The teachers brought up several complaints about their health and quality of life, such as nervousness; hoarseness; back, arm and leg pain; and tingling and swelling in the legs. It was concluded that knowledge of this evidence may contribute to preparing measures for the systematic reorganization of the work and directly influence the teachers' quality of life, affording them better performance in the activity of educating.

Keywords quality of life; teachers; science/education; schools. 


\section{Introdução}

A educação é uma preocupação mundial na qual o trabalho docente contribui de forma significativa na formação e na transformação da sociedade. A categoria docente é uma das mais expostas a ambientes conflituosos e a alta exigência de trabalho, que podem repercutir na saúde física e mental dos professores, assim como no desenvolvimento de suas atividades profissionais (Capel, 1987; Maslach e Jackson, 1981). O estresse ocupacional pode ser constatado entre os docentes pelos seus problemas de saúde e pela redução na frequência ao trabalho (Reis et al., 2006). A qualidade de vida $(\mathrm{QV})$ dos professores pode influenciar as condições de trabalho. Fatores psicológicos ligados ao estresse docente incluem ansiedade, depressão, irritabilidade, hostilidade e exaustão emocional, sendo que entre as repercussões orgânicas mais citadas destacam-se doenças cardiovasculares, labirintite, faringite, neuroses, fadiga, insônia e tensão nervosa (Reis et al., 2006).

O Instituto de Estatística da Organização das Nações Unidas para a Educação, Ciência e Cultura afirma que há um declínio no número de professores/educadores no Brasil, podendo ocasionar um déficit de profissionais capacitados que garantam a universalização da educação básica de qualidade (Werthein e Cunha, 2009). Existe uma estimativa de que até o ano 2015 o Brasil precisará contratar 396 mil novos professores para garantir uma educação para todos (Vedovato e Monteiro, 2008).

A manutenção de um ambiente escolar saudável e voltado para o desenvolvimento comum é um desafio, já que acarreta indagações e incertezas sobre o funcionamento da instituição escolar que deve valorizar o trabalho docente preocupando-se com as condições de trabalho. As circunstâncias sob as quais os docentes mobilizam as suas capacidades físicas, cognitivas e afetivas para atingir os objetivos da produção escolar não devem gerar sobre-esforço ou hipersolicitação de suas funções psicofisiológicas, pois quando não há tempo para a recuperação do cansaço diário do professor são desencadeados ou precipitados os sintomas clínicos que explicariam os índices de afastamento do trabalho (Delcor et al., 2004).

Esta pesquisa visou conhecer o perfil demográfico e ocupacional, além dos indicadores físicos e mentais de saúde e da qualidade de vida, dos educadores das disciplinas da área de ciências (ciências, física, química, matemática e biologia) de uma escola pública de educação básica (séries iniciais e ensinos fundamental e médio) localizada na região central do Rio Grande do Sul, Brasil. 


\section{Qualidade de vida: uma breve revisão}

O termo qualidade de vida, como vem sendo aplicado na literatura médica, não parece ter um único significado (Gill e Feinstein, 1994, apud Fleck et al., 1999). Termos como 'condições de saúde', 'funcionamento social' e 'qualidade de vida' têm sido usados como sinônimos, e a própria definição de qualidade de vida não consta na maioria dos artigos que utilizam ou propõem instrumentos para sua avaliação. A qualidade de vida relacionada com a saúde (Health-related quality of life) e estado subjetivo de saúde (Subjective health status) são conceitos afins centrados na avaliação subjetiva do paciente, mas necessariamente ligados ao impacto do estado de saúde sobre a capacidade do indivíduo de viver plenamente (Fleck et al., 1999).

Segundo Guiselini (1996), falar em qualidade de vida é pensar no caminho da longevidade, sendo seu elemento-chave, além de suprir necessidades básicas, melhorar o estilo de vida, por meio da aquisição de hábitos saudáveis, realizando atividade física, tendo relacionamentos estáveis, duradouros, dieta saudável etc., pois só assim teremos adultos saudáveis hoje e idosos amanhã.

A qualidade de vida é um conceito particular a cada indivíduo ou grupo, apesar de haver consenso de que ela é formada por múltiplos fatores, sendo essa combinação associada a variáveis como estado de saúde, longevidade, satisfação no trabalho, salário, lazer, relações familiares, disposição, prazer e até mesmo a espiritualidade (Nahas, 2001).

Historicamente, os aspectos relevantes para determinação da qualidade de vida foram somente os materiais. Entretanto, com o passar dos tempos, houve uma evolução nesse conceito, valorizando-se aspectos como satisfação e realização pessoal, qualidade nos relacionamentos, opções de lazer, acesso a eventos culturais, percepção de bem-estar geral, entre outros (Rodriguez e Alves, 2008).

Apesar de existirem diversos conceitos sobre o assunto, é fato que o atendimento às necessidades básicas - alimento, moradia, educação e trabalho - formam um componente fundamental para a avaliação da QV. $\mathrm{O}$ tema tornou-se tão amplo que a QV envolve diretamente o bem-estar, a felicidade, os sonhos, a dignidade, o trabalho e a cidadania (Nahas, 2001).

Além da quantidade de fatores que constituem a QV, o entendimento do seu conceito torna-se muito mais fácil de forma intuitiva do que a elaboração de uma definição objetiva e fechada - porque como a qualidade de vida pressupõe o atendimento às necessidades humanas fundamentais, nada mais é do que a medida da própria dignidade humana (Nahas, 2001).

Destaca-se, também, que pessoas com características e condições de vida semelhantes poderão apresentar diferenças na interpretação dos indicadores de QV individuais, em razão de a percepção individual sofrer 
interferência da necessidade de cada um. Com base nesse aspecto, torna-se muito importante para o pesquisador definir claramente o contexto de seu interesse e identificar os domínios que serão avaliados, assim como os instrumentos de medida que utilizará, a fim de evitar interpretações equivocadas (Nahas, 2001).

A busca de um instrumento que avaliasse a qualidade de vida em uma perspectiva genuinamente internacional fez com que a Organização Mundial da Saúde (OMS) organizasse um projeto colaborativo multicêntrico. O resultado deste projeto foi a elaboração do WHOQOL-100, um instrumento de avaliação da qualidade de vida composto por cem itens (Fleck et al., 1999).

\title{
Qualidade de vida de professores da educação básica
}

A Constituição Federal do Brasil trata os fatores de saúde e a qualidade de vida como direitos fundamentais. Para Rodriguez e Alves (2008):

\begin{abstract}
A qualidade de vida no trabalho na maioria das vezes ocorre em função de um conjunto de fatores que independem do profissional. O que se observa é que a atribulação da vida diária, inclusive, precisando dar aulas em diversos lugares para garantir uma vida financeira mais estável, acabam [sic] por levar o profissional docente a não perceber o nível de qualidade de trabalho oferecido. Muitas vezes estão envolvidos em escolas que não oferecem as condições mínimas de exercer suas atividades com dignidade, com respeito e ética, além de receberem um salário muito aquém de sua capacidade, de seu esforço e, especialmente, de sua responsabilidade quanto à educação dos jovens e adolescentes sob sua responsabilidade (Rodriguez e Alves, 2008, p. 7).
\end{abstract}

Superar os vários problemas que se enraízam nas sociedades passa pela redefinição, sem dúvida, do projeto de uma sociedade cujas estruturas devem ser repensadas seriamente, tais como o fator educação e as desestatizações, e pela renovação do discurso e da ação política tipicamente fisiológica e cartorial.

Segundo Paraguay (1990), há estudos ergonômicos para efeito de sugestões de mudanças numa organização do trabalho, com o fim de reduzir a carga laboral e por excelência a mental, com cujas medidas se possa aumentar a autonomia dos trabalhadores e ainda reduzir a pressão temporal, evitar a fadiga e o estresse.

Tornando importante o alerta para o futuro, comenta Carelli (2001, p. 91): “hábitos são decisivos para uma vida longa e feliz. E nunca é tarde para mudar de comportamento e reparar os estragos do fumo, álcool e da vida sedentária". Fernandes (1996) relata que a qualidade de vida no trabalho 
é relevante para o ser humano, pois o nível de satisfação com ele trará influências em seu cotidiano, afetando a autoestima e consequentemente sua produtividade.

A dimensão psicológica do ser humano ainda vagueia pelo campo da pesquisa científica, carecendo de subsídios empíricos devido à sua complexidade e diversidade, tornando-se reflexo da individualização das pessoas. O estudo da motivação se aplica a todo ramo da atividade humana, em especial ao campo organizacional. Muitos estudiosos têm pesquisado para caracterizar os objetivos motivacionais no trabalho, entre eles Maslow, McGregor e Herzberg (Gil, 2001; Bergamini e Coda, 1997; Herzberg, 1997).

A motivação é o conhecimento do conceito da natureza humana, da definição de trabalho e da função individual ou social. É inconteste que a não satisfação pode significar desmotivação quando as frustrações são constantes e conduzem o sujeito até a apatia, o descontentamento, gerando situações de estresse (Aguiar, 1992).

O impacto dos fatores estressantes sobre profissões que requerem condições de trabalho específicas, com grau elevado de relação com o público, como a do professor, tem sido estudado em outros países com a denominação de Síndrome de Burned Out, ou Burnout, que no Brasil recebeu a denominação de Síndrome do Esgotamento Profissional. Burnout seria uma síndrome de exaustão emocional e de atitudes cínicas e negativas dos profissionais em relação aos sentimentos dos indivíduos para os quais dirigem o seu trabalho, visto que os seus recursos emocionais estão esgotados. As consequências da Síndrome de Burnout são sérias para os vários setores relacionados à educação: professor, aluno, instituição (escola) (Reis et al., 2005).

Acredita-se que a capacidade de um indivíduo para controlar situações potencialmente estressantes pode ter profundos efeitos sobre suas funções vitais. Assim, o estresse está intimamente relacionado ao sentido de mudança. Como desde o momento de nossa concepção enfrentamos mudanças continuamente e a manutenção da vida depende justamente da capacidade de nos adaptarmos a essas mudanças, podemos concluir que o estresse é inerente à vida (Delboni, 1997).

Com o excessivo estresse, os indivíduos podem apresentar sintomas e sinais evidenciadores do surgimento ou agravamento de quaisquer doenças. Porém, os sinais de estresse ocupacional podem ser claros para um observador experiente, ou podem ser detectados por meio de pesquisas organizacionais ou de sinais clínicos constatados por um bom médico do trabalho. Com base nisso, programas podem ser desenvolvidos no sentido de reduzir os estressores desnecessários e prejudiciais aos funcionários e à organização. Esses programas 'antiestresse' não se restringem apenas a sistemas organizacionais, estilos gerenciais, técnicas de comunicação etc. O mais indicado 
para evitar o estresse seria a prática de exercícios físicos regularmente, técnicas de relaxamento, meditação etc. Além disso, cursos como gerenciamento de tempo, análise de problemas e tomada de decisões e outros, bastante comuns na área de recursos humanos, podem fornecer subsídios à redução do estresse e à melhoria da qualidade de vida dos indivíduos (Lipp, 2001).

Dentre as numerosas consequências provindas do estresse e da ansiedade segundo Kaplan et al. (1997), podem-se destacar: distúrbios cardiovasculares como a taquicardia e a hipertensão, distúrbios psicológicos como fobias, distúrbios alimentares (anorexia, bulimia ou obesidade), adesão a vícios como o alcoolismo e o tabagismo, isolamento, irritabilidade, agressividade e alienação.

\section{O professor e o exercício da atividade educadora}

O exercício do magistério é uma função antiga, e os problemas decorrentes acompanham o processo desde os primórdios. Alguns estudos brasileiros demonstram uma relação importante entre a saúde dos professores e suas condições de vida e de trabalho (Vedovato e Monteiro, 2008).

No setor da educação, o processo de reestruturação produtiva apresenta novas demandas que impulsionam transformações na organização do trabalho docente. A inserção dos indivíduos no mercado de trabalho exige níveis de escolarização cada vez mais elevados. Para atender às novas demandas de organização dos sistemas de produção, espera-se da escola e, principalmente, do docente a formação de um profissional flexível e polivalente. No Brasil, as transformações na organização do trabalho docente como novas exigências e as competências requeridas modificam a atividade de ensinar e, por não proverem os meios compatíveis, criam uma sobrecarga de trabalho (Gasparini, Barreto e Assunção, 2006).

O campo de ação educacional do professor é a escola, à qual cabe a tarefa de assegurar aos alunos um sólido domínio de conhecimentos e habilidades, fazendo com que eles tenham visão crítica sobre a sociedade na qual estão inseridos. Desse modo, há a formação de indivíduos críticos capazes de participar na luta pela transformação social. Então, o professor exerce um importante papel na construção da sociedade (Libâneo, 1994).

Porém, segundo Vasconcellos (1997), a atividade docente é identificada pela Organização Internacional do Trabalho (OIT) como uma profissão de alto risco, considerada a segunda categoria profissional, em nível mundial, a portar doenças de caráter ocupacional como o estresse. O estresse pode afetar a saúde, a qualidade de vida e a sensação de bem-estar como um todo (Lipp, 2001). 
A OIT definiu as condições de trabalho para os professores ao reconhecer o lugar central que estes ocupam na sociedade, uma vez que são os responsáveis pelo preparo do cidadão para a vida (OIT, 1991). Tais condições buscam basicamente atingir a meta de um ensino eficaz.

A ação educacional é um processo que exige o preparo do docente. Sabese que os professores estão sobrecarregados de trabalho e acabam, muitas vezes, apresentando patologias físicas ou psicológicas em decorrência disso.

O cansaço, a falta de motivação, a ausência de incentivo e os baixos salários são fatores que promovem o descontentamento e o adoecimento desses profissionais. As investigações de Codo (1999) sobre a saúde mental dos professores dos ensinos fundamental e médio em todo o país, abrangendo 1.440 escolas e 30 mil professores, revelaram que $26 \%$ da amostra estudada apresentavam exaustão emocional. Essa proporção alcançou 39\% no Rio Grande do Sul.

Entre as queixas de saúde mais frequentes, estão dores nas costas e nas pernas, e no âmbito psicoemocional, cansaço mental e nervosismo. A presença de calos nas cordas vocais foi referida por $12 \%$ dos professores. A prevalência de distúrbios psíquicos menores foi de $20 \%$, associada a trabalho repetitivo, insatisfação no desempenho das atividades, ambiente intranquilo e estressante, desgaste na relação professor-aluno, falta de autonomia no planejamento das atividades, ritmo acelerado de trabalho e pressão da direção (Delcor et al., 2004). Os professores nas escolas inventam, a todo instante, estratégias e saídas para driblar suas dificuldades cotidianas de trabalho (Silva e Rosso, 2008).

$\mathrm{Na}$ atualidade, o papel do professor extrapolou a mediação do processo de conhecimento do aluno, o que era comumente esperado. Ampliouse a missão do profissional para além da sala de aula, a fim de garantir uma articulação entre a escola e a comunidade. O professor, além de ensinar, deve participar da gestão e do planejamento escolares, o que significa uma dedicação mais ampla, a qual se estende às famílias e à comunidade. As condições de trabalho, ou seja, as circunstâncias sob as quais os docentes mobilizam as suas capacidades físicas, cognitivas e afetivas para atingir os objetivos da produção escolar, podem gerar sobre-esforço ou hipersolicitação de suas funções psicofisiológicas (Gasparini, Barreto e Assunção, 2005).

Ainda a respeito da qualidade de vida dos professores e da educação, Libâneo afirma:

A responsabilidade social da escola e dos professores é muito grande, pois lhes cabe escolher qual concepção de vida e de sociedade deve ser trazida à consideração dos alunos e quais conteúdos e métodos lhes propiciam o domínio dos conhecimentos e a capacidade de raciocínio necessários à compreensão da realidade 
social e à atividade prática na profissão, na política e nos movimentos sociais. A qualidade da educação está diretamente relacionada aos professores. Cabe aos governos a promoção de formas para manter os professores com bom nível de saúde. Através de ações que promovam uma melhor qualidade de vida no trabalho se conseguirá, ao mesmo tempo, promover a saúde dos professores e melhorar o desempenho da educação, o que levará à formação de educandos melhor preparados para atuação na sociedade (Libâneo, 1994, p. 22).

Seguindo a ideia, Freire contribui para o conceito de aprendizagem ao se posicionar sobre o processo de ensinar e aprender:

Ensinar não é transferir conteúdo a ninguém, assim como aprender não é memorizar o perfil do conteúdo transferido no discurso vertical do professor. Ensinar e aprender têm que ver com o esforço metodicamente crítico do professor de desvelar a compreensão de algo e com o empenho igualmente crítico do aluno de ir entrando como sujeito em aprendizagem, no processo de desvelamento que o professor ou professora deve deflagrar. Isso não tem nada a ver com a transferência de conteúdo e fala da dificuldade, mas, ao mesmo tempo, da boniteza e da docência e da decência (Freire, 1996, p. 43).

Para ser professor é necessário ensinar, é inserir-se na história, não é só estar na sala de aula, mas num imaginário político mais amplo (Gadotti, 1995), ou seja, assumindo um compromisso com o outro, para que este possa ser sujeito da sua história e de seu processo de aprendizagem. É impossível pensar em educação sem afirmar que "a leitura do mundo precede a leitura da palavra" (Freire, 1996, p. 42).

Assim, torna-se a escola essencial para auxiliar o aluno na formulação de novos conhecimentos, sendo o lugar onde a intervenção pedagógica desencadeará o processo de ensino-aprendizagem estimulado pelo docente (Vigotsky, 2001). Em especial, o professor de biologia/ciências tem o importante papel de ser o mediador entre o aluno e o conhecimento sobre as características vitais e as relações entre eles e o ambiente.

Segundo os Parâmetros Curriculares Nacionais (PCN) do ensino médio (Brasil, 1999), é papel da escola e do professor fazer com que o aluno tome gosto pelo conhecimento e aprenda a aprender. Porém, muitas vezes, professores doentes não conseguem cumprir de maneira adequada o seu papel no contexto educacional.

De acordo com a Lei de Diretrizes e Bases da Educação Nacional (LDB 9.394/96), artigo 35, inciso III, o professor deve auxiliar no aprimoramento do educando como pessoa humana, incluindo a formação ética e o desenvolvimento da autonomia intelectual e do pensamento crítico (Brasil, 1996a). 
Sabe-se que o trabalho dos professores é cansativo e exige deles, além das horas cumpridas nas escolas, que terminem suas tarefas em casa, como correção de provas e planejamento de aulas. O estado físico ou emocional adoecidos são fatores que levam os professores a se desestimularem e a não proporcionarem aos alunos o aprendizado necessário.

\section{Metodologia}

Realizou-se um estudo epidemiológico de corte transversal (Thomas, Nelson e Silverman, 2007) com professores de uma escola pública localizada em uma cidade da região central do estado do Rio Grande do Sul. Foram incluídos todos os professores regentes nas disciplinas de ciências, física, química, matemática e biologia em efetivo exercício profissional, independentemente do tipo de vínculo empregatício, totalizando o número de sete profissionais.

De acordo com a Resolução n. 196, de 10 de outubro de 1996, do Conselho Nacional de Saúde (Brasil, 1996b), este estudo respeitou os princípios éticos para pesquisas envolvendo seres humanos, o qual foi aprovado pelo Comitê de Ética em Pesquisa com Seres Humanos (CEP) da Universidade Federal de Santa Maria (UFSM).

$\mathrm{Na}$ coleta de dados, foi utilizado um formulário autoaplicado com cinco blocos de questões. No primeiro bloco, foram solicitadas informações acerca das características demográficas, econômicas, ocupacionais e atividades domésticas. O segundo bloco constou de dez questões relativas aos esforços físicos no trabalho, sendo as respostas quantificadas em uma escala do tipo Lickert, de 0 a 3 ( 0 = raramente; $1=$ pouco frequente; $2=$ frequente; e 3 = muito frequente). Este protocolo foi adaptado baseando-se no Job Content Questionnaire (JCQ) (Karasek et al., 1998).

Na pesquisa, o terceiro bloco procurou investigar a saúde física do professor. Nesta etapa, foram classificadas trinta queixas de saúde em uma escala do tipo Lickert, de 0 a 4 ( 0 = não sente; $1=$ raramente; $2=$ pouco frequente; 3 = frequente; e $4=$ muito frequente). $\mathrm{O}$ quarto bloco abordou a saúde mental dos docentes avaliada por meio de um instrumento de detecção de distúrbios psíquicos menores, o Self Reporting Questionnaire-20 (SRQ-20), que é um questionário de identificação de distúrbios psiquiátricos, desenvolvido por Harding et al. (1980) e validado no Brasil para atenção primária (Mari e Williams, 1986) e trabalhadores de informática (Fernandes e Almeida Filho, 1998).

Vários estudos têm sido realizados com esse instrumento em diferentes populações (Nascimento Sobrinho et al., 2003). Nesta pesquisa, desenvolvida com professores, buscou-se classificar como suspeitos de apresentar 
distúrbios psíquicos menores (DPM) aqueles docentes que responderam positivamente a sete ou mais questões dentre as vinte propostas pelo teste, como em estudos anteriores sobre as condições de trabalho dos professores (Reis et al., 2005; Delcor et al., 2004; Araújo, Graça e Araújo, 2003).

$\mathrm{O}$ último bloco incluiu questões acerca dos diagnósticos médicos mais referidos pelos professores desde o início do trabalho como docente.

A coleta de dados foi realizada no período de março a setembro de 2010. Com o intuito de garantir níveis mais elevados de padronização, os professores foram orientados com instruções básicas para o preenchimento dos questionários. Estes foram respondidos na escola e, após o preenchimento, armazenados em envelopes fechados para garantir o anonimato. Os docentes receberam informações a respeito dos objetivos e riscos da pesquisa, com a assinatura do Termo de Consentimento Livre e Esclarecido (TCLE), conforme especifica a Resolução n. 196/96 do Conselho Nacional de Saúde (Brasil, 1996b).

\section{Resultados e discussão}

Participaram do estudo todos os docentes das disciplinas de ciências, física, química, matemática e biologia, totalizando o número de sete profissionais. Os professores pesquisados apresentavam idade média de 44 anos, compreendidos entre 30 e 59 anos, sendo seis do sexo feminino e um do sexo masculino, reafirmando o predomínio feminino na profissão (Silva e Rosso, 2008; Delcor et al., 2004). Quando questionados sobre o número de escolas em que lecionavam, $71 \%$ afirmaram que o faziam em duas escolas, lecionando de trinta a quarenta horas semanais (85\%). Estes resultados vão ao encontro da pesquisa realizada por Silva e Rosso (2008) no Paraná, em que os autores encontraram em mais de $60 \%$ dos entrevistados a jornada de trabalho entre vinte e quarenta horas semanais, sem contar com as horas de trabalho relacionadas à profissão que são realizadas fora do ambiente escolar. $\mathrm{O}$ mesmo estudo revela que muitos professores alegam a falta de tempo para se especializar, ou fazer mestrado ou doutorado em alguma área.

Em outro estudo, no estado de São Paulo, foi descrita uma jornada média de trabalho semanal em mais de uma escola de, aproximadamente, 35 horas (Vedovato e Monteiro, 2008). Já os docentes pesquisados em Vitória da Conquista, na Bahia (Reis et al., 2005), além de trabalharem em outra escola $(59 \%)$ e em mais de duas escolas (9\%), desenvolviam outras atividades remuneradas e não docentes (19\%), o que demonstra a desvalorização da carreira de professor e a consequente baixa remuneração. Muitos professores se veem obrigados a complementar sua renda com trabalhos alterna- 
tivos, tais como aulas particulares, criação de artesanato e venda de produtos, entre outros, para garantir seu sustento e de seus familiares.

As características mais estressantes do trabalho docente são: trabalho repetitivo, intensa concentração em uma mesma tarefa por um longo período, volume excessivo de trabalho, ritmo acelerado, interrupção das tarefas antes de serem concluídas, tempo insuficiente para realização das tarefas, falta de interesse dos colegas de trabalho, exposição a hostilidades, conflitos com os colegas de trabalho e inexistência de processo democrático, segundo o estudo realizado em Jequié, Bahia (Fernandes et al., 2009). Observou-se que a dedicação dos professores da área de ciências exige longos períodos de concentração em uma mesma tarefa para $87 \%$ deles; $71 \%$ disseram realizar suas tarefas, frequentemente, em ritmo acelerado. Resultados igualmente altos foram encontrados por Delcor et al. (2004): $51 \%$ e $67 \%$, respectivamente. Os docentes (80\%), quando questionados em relação à dinâmica de suas aulas de ciências, afirmaram não realizar exercícios práticos com os alunos. Existe uma desmotivação natural para a não realização de aulas práticas pelo fato de muitas escolas não terem laboratórios próprios ou não incentivarem que estas ocorram. Outros fatores encontrados na literatura dizem respeito à falta de tempo para planejamentos das atividades ou necessidade de seguir uma determinação da escola de não aplicar a prática (Kanbach, Laburú e Silva, 2005).

Além da falta de estrutura física ou de hábito de realização das atividades experimentais, pode-se perceber que a maioria dos professores não vê nesse tipo de exercício uma forma de ensino eficiente, mas algo que demanda mais trabalho e horas de envolvimento.

As más condições de trabalho podem estar associadas ao número elevado de afastamentos de professores das salas de aula (Gasparini, Barreto e Assunção, 2005). Os problemas de saúde já afastaram até trinta vezes $25 \%$ dos professores, e o mesmo percentual já sofreu dois acidentes durante a jornada docente. Este índice foi mais de três vezes maior do que o encontrado em Vitória da Conquista, que foi de 7\% (Delcor et al., 2004).

A participação regular e frequente em atividades físicas e esportivas, mesmo que estas sejam muito diversas, constitui um elemento-chave que permite obter efeitos benéficos para a condição física e a saúde (Corbin, Pangrazi e Welk, 1994). Segundo Pieron (2004), a pouca frequência na participação não cumpre as recomendações mínimas para que haja efeitos ligados à saúde. Para $28 \%$ dos professores, a prática de exercícios físicos acontece cinco vezes por semana, e para $40 \%$, as atividades de lazer são realizadas quatro vezes ao mês. Vedovato e Monteiro (2008) verificaram em seu estudo que $93 \%$ dos professores paulistas realizavam atividades de lazer e que $56 \%$ praticavam atividade física regularmente pelo menos três vezes na semana. Em outro estudo, a atividade física fora do trabalho foi referida 
por $38 \%$, e $53 \%$ dos professores disseram que dedicavam algum tempo semanal ao lazer durante a semana (Delcor et al., 2004).

Foi identificado, em um estudo realizado com 250 professores do ensino fundamental do município baiano de Vitória da Conquista (Delcor et al., 2004), que vários aspectos contribuem para a diminuição da vitalidade do professor. Entre eles, os mais fortemente percebidos foram: ritmo acelerado de trabalho $(67 \%)$, ritmo frenético de trabalho $(54 \%)$, posições da cabeça e braços inadequadas e incômodas (53\%) e longos períodos de intensa concentração em uma mesma tarefa $(51 \%)$, chamando a atenção para o fato de que a saúde física prejudicada pode incidir na prática da docência, acarretando maior número de faltas ao trabalho, assim como maior desinteresse na realização e na inovação da prática educacional (Rocha e Fernandes, 2008).

Outro bloco de questões do Job Content Questionnaire (JCQ) modificado, que os professores da área de ciências dessa escola responderam, diz respeito aos esforços físicos no trabalho. Quando perguntados sobre as queixas de saúde, $28 \%$ dos professores relataram que não as possuem; contudo, $71 \%$ disseram tê-las com alguma frequência. Na pesquisa realizada por Silva e Rosso (2008), 40\% dos professores apresentaram cansaço devido às condições físicas impostas pelo trabalho, enquanto no trabalho de Delcor et al. (2004) 59\% acusaram cansaço mental.

Os professores de algumas escolas estaduais de São Paulo foram pesquisados por Vedovato e Monteiro (2008), e 95\% deles consideraram o seu trabalho cansativo e desgastante, além de atribuírem ao trabalho mental um grau mais extenuante ( $46 \%$ ) do que o físico (30\%).

O esquecimento, na maioria dos professores (57\%), é uma queixa que não ocorre, apesar de $42 \%$ admitirem que isso aconteça com alguma frequência. Este dado aproxima-se dos encontrados por Silva e Rosso (2008), em que metade dos professores investigados nas escolas públicas paranaenses de Ponta Grossa relatou ter problemas de esquecimento.

Da mesma forma que o esquecimento, a insônia não faz parte das queixas sobre saúde da maioria dos professores (57\%); mesmo assim, 42\% relataram que esse episódio ocorria normalmente. Já a sonolência está presente em $71 \%$ dos docentes.

Ao serem questionados a respeito do nervosismo, 28\% responderam que não o sentem, mas $71 \%$ experimentam essa sensação. A maior parte dos professores (57\%) que participaram da pesquisa disse que não costuma se sentir irritada, porém $42 \%$ relataram se sentir dessa maneira.

Queixas relacionadas à má digestão estão presentes em 33\% dos professores. Em relação à indisposição gástrica causada pela azia/queimação, a grande maioria (85\%) afirmou não sentir, enquanto apenas $14 \%$ informaram essa queixa de saúde. 
A prática da docência, a longo prazo, pode levar a várias patologias musculoesqueléticas e psicológicas, muitas vezes relacionadas a quadros álgicos intensos, podendo acarretar absenteísmo. A docência vem sofrendo constantes alterações no decorrer de sua história, embora o professor não tenha tido condições de criar meios para se adaptar às mudanças, o que levou ao surgimento de desequilíbrios na estrutura corporal e dores (Fernandes et al., 2009).

Segundo Fernandes et al. (2009), os determinantes e condicionantes do processo saúde-doença na classe docente são complexos. Um dos aspectos que fazem parte dessa dinâmica diz respeito às questões físicas, relacionadas ao sistema osteomuscular dos indivíduos. Sobre esse questionamento, os escores apresentaram semelhança para dor nos braços/ombros, dor/formigamento nas pernas e inchaço nas pernas, sendo que $42 \%$ dos professores informaram que não têm esses sintomas. Porém, verificou-se que 57\% dos docentes costumam apresentar esses sintomas. A dor nas costas manifestase em $71 \%$ dos profissionais (Tabela 1 ).

Tabela 1

\begin{tabular}{lcc}
\hline \multicolumn{2}{l}{ Queixas de saúde dos professores de ciências de uma escola pública do Rio Grande do Sul, Brasil, 2010} \\
\hline Sintoma & Não (\%) & Sim (\%) \\
\hline Dor nos braços/ombros & $42,86(n=3)$ & $57,14(n=4)$ \\
Dor nas costas & $28,57(n=2)$ & $71,43(n=5)$ \\
Dor/formigamento nas pernas & $42,86(n=3)$ & $57,14(n=4)$ \\
Inchaço nas pernas & $42,86(n=3)$ & $57,14(n=4)$ \\
\hline
\end{tabular}

Fonte: Os autores, com base nos dados coletados na pesquisa.

No estudo realizado por Delcor et al. (2004), destacaram-se as queixas de saúde relacionadas à postura, como dor nos braços/ombros (52\%), dor nas costas (51\%) e dor nas pernas/formigamento (47\%). Silva e Rosso (2008) encontraram um indicativo de $60 \%$ de dores nas costas e na coluna dos professores por eles pesquisados, o que pode ser um reflexo da má postura desses docentes, em pé ou sentados.

As queixas relacionadas aos problemas de uso da voz apresentam escores diferentes para cada sintoma, conforme a Tabela 2. Segundo Silva e Rosso (2008), os professores alegam que os alunos falam muito alto, o que provoca maior intensidade no uso da voz dos docentes. Nesta pesquisa, a perda temporária da voz foi o sintoma que menos esteve presente nesses professores $(57 \%)$, se comparada com a dor de garganta e a rouquidão (71\%). Os índices encontrados por Delcor et al. (2004) são alarmantes: $46 \%$ relataram dor na garganta, 93\% deles referiram uso intensivo da voz, 
$62 \%$ cansavam-se para falar e $57 \%$ faziam força para serem ouvidos. Além disso, o estudo mostrou que $59 \%$ dos professores da rede particular de ensino de Vitória da Conquista referiram rouquidão nos últimos seis meses.

Tabela 2

Queixas relacionadas aos problemas de uso da voz em professores de ciências de uma escola pública do Rio Grande do Sul, Brasil, 2010

\begin{tabular}{lll}
\hline Sintoma & Não $(\%)$ & Sim $(\%)$ \\
\hline Dor de garganta & $28,57(n=2)$ & $71,43(n=5)$ \\
Rouquidão & $28,57(n=2)$ & $71,43(n=5)$ \\
Perda temporária da voz & $42,86(n=3)$ & $57,14(n=4)$ \\
\hline
\end{tabular}

Fonte: Os autores, com base nos dados coletados na pesquisa.

Para os professores da área de ciências dessa escola, as questões ligadas aos sintomas alérgicos demonstraram que o entupimento nasal, a rinite e a irritação nos olhos acompanham $57 \%$ desses docentes com alguma frequência. Tosse e coriza também estão presentes entre os sintomas que se manifestam em $43 \%$ dos professores entrevistados, conforme a Tabela 3. No trabalho desenvolvido por Silva e Rosso (2008), 40\% dos professores que participaram da pesquisa relataram ter problemas respiratórios.

Tabela 3

Questões ligadas aos sintomas alérgicos em professores de ciências de uma escola pública do Rio Grande do Sul, Brasil, 2010

\begin{tabular}{lll}
\hline Sintoma & Não $(\%)$ & $\operatorname{Sim}(\%)$ \\
\hline Entupimento nasal & $42,86(n=3)$ & $57,14(n=4)$ \\
Rinite & $42,86(n=3)$ & $57,14(n=4)$ \\
Tosse & $57,14(n=4)$ & $42,86(n=3)$ \\
Coriza & $57,14(n=4)$ & $42,86(n=3)$ \\
Irritação nos olhos & $42,86(n=3)$ & $57,14(n=4)$ \\
\hline
\end{tabular}

Fonte: Os autores, com base nos dados coletados na pesquisa.

A Tabela 4 apresenta outras queixas de saúde que foram relatadas pelos professores. Entre os problemas mencionados, aparecem em maior percentual a queda de cabelo, a redução da visão e as tonturas (57\%) e os problemas digestivos (43\%).

De acordo com Silva e Rosso (2008), 60\% dos professores das escolas públicas de Ponta Grossa (PR) disseram sentir falta de ar durante as aulas e 
também durante o trajeto até a sala de aula, subindo e descendo escadas. Segundo esses autores, o grupo ocupacional estudado por eles apresentou altas queixas sobre seu trabalho docente, sobre os problemas relacionados com a saúde física e psíquica e também problemas relacionados à organização do seu trabalho.

Tabela 4

Outras queixas de saúde relatadas pelos professores de ciências de uma escola pública do Rio Grande do Sul, Brasil, 2010

\begin{tabular}{lll}
\hline Sintoma & Não $(\%)$ & Sim $(\%)$ \\
\hline Queda dos cabelos & $42,86(n=3)$ & $57,14(n=4)$ \\
Redução da visão & $42,86(n=3)$ & $57,14(n=4)$ \\
Problemas digestivos & $57,14(n=4)$ & $42,86(n=3)$ \\
Tonturas & $42,86(n=3)$ & $57,14(n=4)$ \\
\hline
\end{tabular}

Fonte: Os autores, com base nos dados coletados na pesquisa.

Os diagnósticos médicos mais referidos por esses professores, com incidência de $27 \%$, foram calos nas cordas vocais, lesões por esforços repetitivos, sinusite crônica, hipertensão arterial e lombalgia (Tabela 5). Para Vedovato e Monteiro (2008), as doenças com diagnósticos médicos mais citadas foram: musculoesqueléticas e respiratórias (27\%), acidentes e doenças digestivas (22\%), transtornos mentais $(21 \%)$, cardiovasculares $(19 \%)$, neurológicas $(19 \%)$, endócrinas $(17 \%)$, de pele $(16 \%)$ e geniturinárias $(11 \%)$.

Já na pesquisa realizada por Delcor et al. (2004), os diagnósticos médicos referidos mais frequentes são: varizes em membros inferiores (36\%), gastrite ou esofagite $(24 \%)$, infecções do trato urinário (18\%), sinusite crônica $(18 \%)$, lesão por esforço repetitivo (LER) (18\%) e calos nas cordas vocais $(13 \%)$.

Tabela 5

Diagnósticos médicos mais referidos pelos professores de ciências de uma escola pública do Rio Grande do Sul, Brasil, 2010

\begin{tabular}{ll}
\hline Sintoma & $\operatorname{Sim}(\%)$ \\
\hline Calos nas cordas vocais & $28,57(n=2)$ \\
Lesões por esforços repetitivos (LER) & $28,57(n=2)$ \\
Sinusite crônica & $28,57(n=2)$ \\
Hipertensão arterial & $28,57(n=2)$ \\
Lombalgia & $28,57(n=2)$
\end{tabular}

Fonte: Os autores, com base nos dados coletados na pesquisa. 
De acordo com as Nações Unidas, o mundo será mais velho, mais populoso e mais pobre aproximadamente no ano de 2050. Como as condições ao seu redor criam tensão (estresse) e ansiedade, mais pessoas serão suscetíveis a transtornos mentais (Trigo, Teng e Hallak, 2007).

A avaliação da saúde mental dos professores pesquisados neste estudo demonstrou que os sintomas mais frequentes foram sentir-se nervoso, tenso ou preocupado (83\%). Metade dos docentes referiu encontrar dificuldades para realizar com satisfação suas atividades diárias. O sentimento de tristeza também foi relatado por $50 \%$ dos professores. Questões como assustar-se com facilidade e dificuldade de pensar com clareza estiveram presentes em $1 / 3$ dos pesquisados.

Porto et al. (2006) realizaram um estudo transversal com professores da educação infantil e do ensino fundamental de Vitória da Conquista, da rede pública municipal e de escolas particulares. A prevalência global de distúrbios psíquicos foi de $44 \%$ nos 1.016 professores com informação disponível entre os 1.024 investigados. As pressões na saúde mental mundial estão se intensificando.

Trigo, Teng e Hallak (2007), em estudo sobre a saúde mental dos professores dos ensinos fundamental e médio em todo o país, abrangendo 1.440 escolas e 30 mil professores, revelaram que $26 \%$ da amostra estudada apresentavam exaustão emocional. Essa proporção variou de 17\% (Minas Gerais e Ceará) a 39\% (Rio Grande do Sul).

No estudo de Delcor et al. (2004), os resultados apontam uma prevalência de distúrbios psíquicos menores em $41 \%$, variando de $17 \%$ a $66 \%$, a depender da escola onde o profissional se inseria, estando fortemente associada ao trabalho repetitivo, ao volume excessivo e ao ritmo acelerado de trabalho, à intensa concentração em uma mesma tarefa e ao tempo insuficiente para a realização de outras.

A investigação das condições de saúde e trabalho de professores da rede particular de ensino do estado da Bahia destaca grande proporção de adoecimento numa população relativamente jovem, com queixas importantes relacionadas ao funcionamento psíquico, como cansaço mental e nervosismo. O referido grupo apresentou maior prevalência de problemas gerais de saúde, em comparação com o grupo de professores sem distúrbios psíquicos menores. No estudo, foram associados aos distúrbios psíquicos menores os fatores que dizem respeito à organização do trabalho, tais como trabalho repetitivo, insatisfação no desempenho das atividades, ambiente intranquilo e estressante, desgaste da relação professor-aluno, falta de autonomia no planejamento das atividades e ritmo acelerado de trabalho e pressão da direção (Gasparini, Barreto e Assunção, 2006). 


\section{Considerações finais}

Com base nos resultados encontrados, podemos concluir que a maioria dos sete professores da amostra estudada apresenta alguma queixa de saúde. As queixas físicas de maior expressão foram as dores nas costas, pernas e braços/ombros. Já o desgaste emocional foi representado pelo nervosismo, tristeza e dificuldade para realização das atividades diárias. Os desgastes físicos e emocionais identificados na pesquisa podem sugerir um déficit na qualidade de vida desses docentes, assim como uma desqualificação intelectual, em âmbito tanto individual quanto coletivo.

Essas evidências, por sua vez, poderão gerar e sustentar medidas para a reorganização da sistemática de trabalho e influenciar diretamente na qualidade de vida dos professores e na atividade de educar. Atualmente, o professor se depara, na escola, com a necessidade de desempenhar vários papéis, muitas vezes contraditórios, que lhe exigem manter o equilíbrio em várias situações.

Outros estudos devem ser somados a este para podermos avaliar a qualidade de vida dos educadores, já que diversos problemas relacionados à atividade docente, à saúde e à segurança no trabalho devem ser considerados. As reflexões e as ações geradas devem visar à busca de alternativas para possíveis modificações, não só na esfera de seu trabalho e de suas relações interpessoais, mas também na ampla gama de fatores que determinam aspectos constituintes da qualidade de vida, para que os professores exerçam sua atividade profissional com satisfação e saúde.

Diante disso, é urgente que a sociedade, como um todo, reflita sobre esse problema e comece a enxergar os professores como pessoas que precisam de tempo para cuidar da sua saúde, ou seja: os professores devem buscar ter suas horas de lazer e descanso para que possam, saudavelmente, exercer sua grande missão.

\section{Colaboradores}

Este manuscrito, cujo conteúdo foi proposto e organizado por Liliani Mathias Brum, é fruto de análise, elaboração e redação comum realizada por todos os autores. Os dados apresentados são parte da tese de doutorado em Educação em Ciência Quimica da vida e saúde, Universidade Federal de Santa Maria, a qual foi aprovada pelo Comitê de Ética em Pesquisa com Seres Humanos. Os autores afirmam não haver conflito de interesses. 


\section{Notas}

1 Coordenadora do Serviço de Perícia Médica da Universidade Federal de Santa Maria (UFSM), Santa Maria, Rio Grande do Sul, Brasil. Mestre em Nanociências pelo Centro Universitário Franciscano (Unifra/RS). <lilianibrum@gmail.com>

Correspondência: Rua Barão do Triunfo, 2.031, apto. 403, CEP 97015-070, Santa Maria, Rio Grande do Sul, Brasil.

2 Pesquisadora do Núcleo de Estudos em Exercício Físico e Saúde da Universidade Federal de Santa Maria (UFSM), Santa Maria, Rio Grande do Sul, Brasil. Mestre em Farmacologia pela Universidade Federal de Santa Maria (UFSM). <cati.razambuja@hotmail.com>

3 Biomédico. Graduado em Biomedicina pelo Centro Universitário Franciscano (Unifra), Santa Maria, Rio Grande do Sul, Brasil.<joaofprezer@hotmail.com>

4 Professora de Biologia na Educação Básica na Secretaria Estadual de Educação do Rio Grande do Sul, Brasil. Mestre em Educação em Ciências pela Universidade Federal de Santa Maria (UFSM). < daianatemp@yahoo.com.br>

5 Professora do Departamento de Morfologia da Universidade Federal de Santa Maria (UFSM), Santa Maria, Rio Grande do Sul, Brasil. Mestre em Educação pelo Centro Universitário Franciscano (Unifra). <criskoh@terra.com.br>

6 Professor associado do Departamento de Ciências Administrativas da Universidade Federal de Santa Maria (UFSM), Santa Maria, Rio Grande do Sul, Brasil. Doutor em Engenharia de Produção pela Universidade Federal de Santa Catarina (UFSC).<lflopes67@yahoo.com.br>

7 Professora associada do Departamento de Química do Centro de Ciências Naturais e Exatas da Universidade Federal de Santa Maria (UFSM), Santa Maria, Rio Grande do Sul, Brasil. Doutora em Bioquímica pela Universidade Federal do Paraná (UFPR). $<$ mariachitolina@gmail.com>

\section{Referências}

AGUIAR, Maria A. F. Psicologia aplicada à administração. São Paulo: Excellus e Consultoria, 1992.

ARAÚJO, Tânia M.; GRAÇA, Cláudia C.; ARAÚJO, Edna. Estresse ocupacional e saúde: contribuições do modelo demandacontrole. Ciência \& Saúde Coletiva, Rio de Janeiro, v. 8, n. 4, p. 991-1003, 2003.
BERGAMINI, Cecília W.; CODA, Roberto (Orgs.). Psicodinâmica da vida organizacional: motivação e liderança. 2. ed. São Paulo: Atlas, 1997.

BRASIL. Lei n. 9.394/96, de 20 de dezembro de 1996. Estabelece as Diretrizes e Bases da Educação Nacional. Diário Oficial da República Federativa do Brasil, Poder Executivo, Brasília, DF, n. 248, 23 dez. 1996a. 
Ministério da Saúde. Conselho Nacional de Saúde. Resolução n. 196, de 10 de outubro de 1996b. Disponível em: $<$ www.datasus.gov.br/conselho/resol96/ RES19696.htm>. Acesso em: 1 jun. 2011.

Ministério da Educação. Parâmetros Curriculares Nacionais: Ensino Médio. Brasília: Secretaria de Educação Média e Tecnológica, 1999.

CAPEL, Susan. The incidence of and influences on stress and burnout in secondary school teachers. British Journal of Educational Psychology, Edinburg, v. 57, p. 279288, 1987.

CARELLI, Gabriela. O poder grisalho: ricos como nunca, idosos americanos trocam o pijama pelos prazeres da vida. Sessão Sociedade. Veja, São Paulo, ed. 1700, ano 34, n. 19, p. 91-92, 16 maio 2001.

CODO, Wanderley (Coord.). Educação: carinho e trabalho. Petrópolis: Vozes, 1999.

CORBIN, Charles B.; PANGRAZI, Robert P.; WELK, Greg J. Toward an understanding of appropriate physical activity levels for youth. President's Council on Physical Fitness and Sports Research Digest Phys. Fitness Res. Digest, Rockville,v. 1, n. 8, p. 1-8, 1994.

DELBONI, Thais H. Vencendo o stress. São Paulo: Makron Books, 1997.

DELCOR, Nuria S. et al. Condições de trabalho e saúde dos professores da rede particular de ensino de Vitória da Conquista, Bahia, Brasil. Cadernos de Saúde Pública, Rio de Janeiro, v. 20, n. 1, p. 187-196, 2004.

FERNANDES, Eda. Qualidade de vida no trabalho: como medir para melhorar. Salvador: Casa da Qualidade, 1996.

FERNANDES, Marcos H. et al. Estilo de vida de professores universitários: uma estratégia para a promoção da saúde do trabalhador. Revista Brasileira em Promoção da Saúde, Fortaleza, v. 22, n. 2, p. 94-99, 2009.
FERNANDES, Sônia R. P.; ALMEIDA FILHO, Naomar. Validação do SRQ-20 em amostra de trabalhadores em informática. Revista Brasileira de Saúde Ocupacional, São Paulo, v. 89, n. 24 ?, p. 105-112, 1998.

FLECK, Marcelo P. A. et al. Desenvolvimento da versão em português do instrumento de avaliação de qualidade de vida da OMS (WHOQOL-100). Revista Brasileira de Psiquiatria, São Paulo, v. 21, n. 1, p. 19-28, 1999.

FREIRE, Paulo. Pedagogia da autonomia: saberes necessários à prática educativa. 2. ed. Rio de Janeiro: Paz e Terra, 1996.

GADOTTI, Moacir. História das idéias pedagógicas. São Paulo: Ática, 1995.

GASPARINI, Sandra M.; BARRETO, Sandhi M.; ASSUNÇÃO, Ada A. O professor, as condições de trabalho e os efeitos sobre sua saúde. Educação e Pesquisa, São Paulo, v. 31, n. 2, p. 189-199, 2005.

Prevalência de transtornos mentais comuns em professores da rede municipal de Belo Horizonte, Minas Gerais, Brasil. Cadernos de Saúde Pública, Rio de Janeiro, v. 22, n. 12, p. 2679-2691, 2006.

GIL, Antônio C. Gestão de pessoas: enfoque nos papéis profissionais. São Paulo: Atlas, 2001.

GUISELINE, Mauro A. Qualidade de vida um programa prático para um corpo saudável. 2. ed. São Paulo: Gente, 1996.

HARDING, Timothy W. et al. Mental disorders in primary health care: a study of their frequency and diagnosis in four developing countries. Psychological Medicine, Cambrigde, v. 10, n. 2, p. 231-241, 1980.

HERZBERG, Frederick. Mais uma vez: como motivar seus funcionários? In: VROON, Victor H. (Org.). Gestão de pessoas, não de pessoal: os melhores métodos de motivação e avaliação de desempenho. Rio de Janeiro: Campus, 1997. p. 55-82. (Tradução de Manage people, not personnel, Harvard Business Review Book). 
KANBACH, Bruno G.; LABURÚ, Carlos E.; SILVA, Osmar H. M. Razões para a não utilização de atividades práticas por professores de física no ensino médio. In: SIMPÓSIO NACIONAL DE ENSINO DE FÍSICA, 16. Anais... Rio de Janeiro: SNEF, 2005.

KAPLAN, Harold I. et al. Compêndio de psiquiatria: ciências do comportamento e psiquiatria clínica. 7. ed. Porto Alegre: Artes Médicas, 1997.

KARASEK, Robert et al. The Job Content Questionnaire (JCQ): an instrument for internationally comparative assessments of psychosocial job characteristics. Journal of Occupacional Health Phsighology, Washington, v. 3, n. 4, p. 322-355, 1998.

LIBÂNEO, José C. Didática. São Paulo: Cortez, 1994.

LIPP, Marilda E. N. (Org.). Pesquisas sobre stress no Brasil: saúde, ocupações e grupos de risco. Campinas: Papirus, 2001.

MARI, Jair J.; WILLIAMS, Paul. A validity study of a Psychiatric Screening Questionnaire (SRQ-20) in primary care in the city of São Paulo. Brazilizan Journal of Psychiatry, São Paulo, v. 148, p. 23-26, 1986.

MASLACH, Christina E.; JACKSON, Susan E. The measurement of experienced burnout. Journal of Occupational Behavior, Nova York, v. 2, p. 99-113, 1981.

NASCIMENTO SOBRINHO, Carlito L. et al. Condições de trabalho e saúde mental dos médicos de Salvador, Bahia, Brasil. Cadernos de Saúde Pública, Rio de Janeiro, v. 22, n. 1, p. 131-140, 2006.

NAHAS, Markus V. Atividade física, saúde e qualidade de vida: conceitos e sugestões para um estilo de vida ativo. 2. ed. Londrina: Midiograf, 2001.

ORGANIZAÇÃO INTERNACIONAL DO TRABALHO (OIT). Personal docente: los retos del decenio de 1990. Ginebra: Oficina Internacional del Trabajo, 1991.
PARAGUAY, Ana I. B. B. Estresse, conteúdo e organização do trabalho: contribuição da ergonomia para melhoria das condições de trabalho. Revista Brasileira de Saúde Ocupacional, Brasília, v. 18, n. 70, p. 40-43, 1990.

PIERON, Maurice. Estilo de vida, práticas de atividades físicas e esportivas, qualidade de vida. Fitness \& Performance Journal, Rio de Janeiro, v. 3, n. 1, p. 10-18, 2004.

PORTO, Lauro A. et al. Associação entre distúrbios psíquicos e aspectos psicossociais do trabalho de professores. Revista de Saúde Pública, São Paulo, v. 40, n. 5, p. 818826, 2006.

REIS, Eduardo J. F. B. et al. Trabalho e distúrbios psíquicos em professores da rede municipal de Vitória da Conquista, Bahia, Brasil. Cadernos de Saúde Pública, Rio de Janeiro, v. 21, n. 5, p. 1480-1490, 2005.

Docência e exaustão emocional. Educação e Sociedade, Campinas, v. 27, n. 94, p. 229-253, 2006.

ROCHA, Vera M.; FERNANDES, Marcos H. Qualidade de vida de professores do ensino fundamental: uma perspectiva para a promoção da saúde do trabalhador. Jornal Brasileiro de Psiquiatria, Rio de Janeiro, v. 57, n. 1, p. 23-27, 2008.

RODRIGUEZ, Martius V. R. Y.; ALVES, Joemar B. Qualidade de vida dos professores: um bem para todos. In: CONGRESSO NACIONAL DE EXCELÊNCIA EM GESTÃO, 4. Niterói, 2008. p. 2-23. Disponível em: $<$ www.latec.uff.br/cneg/documentos/anais _cneg4/T7_0049_0018.pdf >. Acesso em: 31 maio 2011.

SILVA, Guilherme L. F.; ROSSO, Ademir J. As condições do trabalho docente dos professores das escolas públicas de Ponta Grossa, PR. In: CONGRESSO NACIONAL DE EDUCAÇÃO, EDUCERE, 8., Curitiba, 2008. Disponível em: <www.pucpr.br/eventos/ educere/educere2008/anais/pdf/495_536.pdf > . Acesso em: 31 maio 2011. 
THOMAS, Jerry R.; NELSON, Jack K.; SILVERMAN, Stephen J. Métodos de pesquisa em atividade física. 5. ed. Porto Alegre: Artmed, 2007.

TRIGO, Telma R.; TENG, Chei T.; HALLAK, Jaime Eduardo C. Síndrome de Burnout ou estafa profissional e os transtornos psiquiátricos. Revista de Psiquiatria Clínica, São Paulo, v. 34, n. 5, p. 223-233, 2007.

VASCONCELLOS, Celso S. Construção do conhecimento em sala de aula. São Paulo: Libertad, 1997.
VEDOVATO, Tatiana G.; MONTEIRO, Maria I. Perfil sociodemográfico e condições de saúde e trabalho dos professores de nove escolas estaduais paulistas. Revista da Escola de Enfermagem da USP [online], São Paulo, v. 42, n. 2, p. 290-297, 2008. Disponível em: <www.scielo.br/pdf/reeusp/v42n2/all.pdf>. Acesso em: 13 jul. 2011.

VIGOTSKI, Lev S. A construção do pensamento e da linguagem. São Paulo: Martins Fontes, 2001.

WERTHEIN, Jorge; CUNHA, Célio (Orgs.). Ensino de ciências e desenvolvimento: o que pensam os cientistas. 2. ed. Brasília: Unesco, Instituto Segari, 2009.

Recebido em 08/07/2011

Aprovado em 21/08/2011 